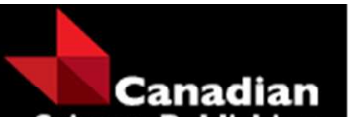

Science Publishing

Canadian Journal of Forest Research

Revue canadienne de recherche forestière

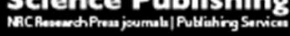

\title{
A differentiable optimization model for the management of single-species, even-aged stands
}

\begin{tabular}{|r|l|}
\hline Journal: & Canadian Journal of Forest Research \\
\hline Manuscript ID & cjfr-2016-0237.R2 \\
\hline Manuscript Type: & Article \\
\hline Date Submitted by the Author: & 05-Nov-2016 \\
\hline Complete List of Authors: & $\begin{array}{l}\text { Arias-Rodil, Manuel; Escola Politécnica Superior, Universidade de Santiago } \\
\text { de Compostela, } \\
\text { Diéguez-Aranda, Ulises; Escuela Politécnica Superior (USC), Agroforestry } \\
\text { Engeneering } \\
\text { Vazquez-Mendez, Miguel; University of Santiago de Compostela, Applied } \\
\text { Mathematics }\end{array}$ \\
\hline Keyword: & $\begin{array}{l}\text { forest simulation, silvicultural prescription, dynamic growth model, } \\
\text { derivative-free optimization, sequential quadratic programming }\end{array}$ \\
\hline
\end{tabular}

\section{SCHOLARONE ${ }^{m}$}

Manuscripts 
${ }_{6}{ }^{1}$ Unidad de Gestión Forestal Sostenible, Departamento de Ingeniería Agroforestal, Universidade 7 de Santiago de Compostela. Escuela Politécnica Superior, C/ Benigno Ledo, Campus Terra, 827002 Lugo, Spain.

$9^{2}$ Grupo de Simulación y Control, Departamento de Matemática Aplicada, Universidade de

10 Santiago de Compostela. Escuela Politécnica Superior, C/ Benigno Ledo, Campus Terra, 27002

11 Lugo, Spain.

${ }_{12}^{*}$ * Corresponding author:

13 Escuela Politécnica Superior

14 C/ Benigno Ledo, Campus Terra

1527002 Lugo, Spain

${ }_{16}$ Tel: +34 982823300

17 Fax: +34 982823001

18 E-mail address: ulises.dieguez@usc.es 


\section{Abstract}

This paper presents a model for optimizing the management of single-species, even-aged stands. The model comprises a number of state variables, given by functions initially differentiable with respect to time, which cease to be due to the discontinuities that cause instant silvicultural treatments. Nevertheless, the proposed model maintains its differentiability with respect to the decision variables (timing, type, and intensity of each thinning, and rotation age). This allows to formulate the problem of optimal management of this type of stands as a linearly constrained smooth optimization problem, which can be efficiently solved by any derivative-based optimization method. The effectiveness of this formulation is showed by using a Sequential Quadratic Programming (SQP) algorithm to design the optimal management of Pinus pinaster Ait. in Asturias (NW Spain) from an economic perspective. These results are compared with those obtained with two methods that do not require derivatives. The SQP, as representative of gradient-type methods, proved robust and much more efficient than the derivative-free methods.

Keywords: forest simulation, silvicultural prescription, dynamic growth model, derivative-free optimization, sequential quadratic programming. 


\section{Introduction}

Stand growth and yield prediction and its response to silvicultural treatments have always been a matter of interest for forest researchers, as the key to proper management is the adequate knowledge of the growth process of forest species. In this sense, empirical models are preferred to process-based models or hybrid models for single-species, even-aged stands (Burkhart and Tomé, 2012, p. 2). The former are usually categorized according to their modelling entity (Weiskittel et al., 2011, p. 53-83) as whole-stand, size-class and individual-tree models. Whole-stand models represent an adequate alternative for the management of single-species, even-aged stands, as they are able to provide accurate estimates, while data inputs can be easily obtained (Weiskittel et al., 2011, p. 53). The state-space approach (García, 1994) is still a common alternative for the development of empirical whole-stand growth models, e.g. in Canada (García, 2013), USA (García et al., 2011), Switzerland (Álvarez-González et al., 2010), or NW Spain (Gómez-García et al., 2015; Arias-Rodil et al., 2015a). Their implementation in computer programs allows simulation of different silvicultural prescriptions and evaluation of their consequences in the forest system (Burkhart and Tomé, 2012, p. 428-429).

Management of any resource requires a planning stage which implies a decision making process. In forestry, at least four planning levels may be considered: tree, stand, forest, and landscape. The stand level is frequently used to develop plans of action for those landowners who have small holdings (Bettinger et al., 2009, p. 125), in many cases planted with trees of the same species and age. The management of these stands from an economic perspective requires to decide about the optimal timber rotation and the optimal number, type, intensity, and timing of thinning.

As the number of options in the stand-level management problem is unlimited, an automatic search procedure (optimization algorithm) must be used to generate and evaluate alternatives with respect to the value of the specified objective function. A number of algorithms have been used for optimizing stand-level management, which differ mainly in whether they require discretization of the decision variables (thus reducing the number of solutions to evaluate) or 
not. In the former, the search is reduced to the network of nodes defined in a discrete space of solutions where the algorithm reaches the global maximum. The problem is to strike a balance between information loss due to the discretization and the computation time required, which increases exponentially with the number of possible solutions. Dynamic programming (e.g. Arimizu, 1958; Amidon and Akin, 1968; Díaz-Balteiro and Rodríguez, 2006) and depth first search (Arias-Rodil et al., 2015b) are examples of methods of this type that have been used in stand-level optimization. Concerning approaches that do not require discretization of the decision variables, direct search methods have been considered (e.g. Cao, 2010; Pukkala and Kellomäki, 2012; Tahvonen et al., 2013). Their disadvantage is that they do not assure reaching the global optimum (Valsta, 1993), although they usually provide reasonably good results in reduced computing times, not requiring the use of derivatives. Within this group, there are methods that use a single solution vector and others that use multiple solution vectors, so-called population-based methods (Pukkala, 2009).

In this study we formulate a model to optimize the management of single-species, evenaged stands for which a dynamic growth model is available. Our growth model comprises a number of state variables, given by functions initially smooth (class $C^{\infty}$ ), which cease to be when thinnings are simulated. These silvicultural treatments induce, in the moments they are applied, sudden changes in the values of the state variables, causing discontinuities at those moments. Nevertheless, and as shown in the following sections, the model remains differentiable with respect to the decision variables (timing, type, and intensity of each thinning, and rotation age). This allows us to formulate the problem of the optimal management of this type of stands as a differentiable optimization problem with linear constraints. This new formulation enables the use of derivative-based optimization methods, consequently opening up a huge range of possibilities to solve the problem. As an example, in this work we used a Sequential Quadratic Programming (SQP) algorithm to design the optimal management of Pinus pinaster Ait. in Asturias (NW Spain) from an economic perspective. We compared our approach with two directsearch methods: Hooke and Jeeves (1961) method (HJ), the most commonly used in forestry 
(e.g. Roise, 1986; Miina, 1996; Pukkala et al., 2014; Pasalodos-Tato et al., 2016), and Differential Evolution (DE, Storn and Price, 1997), which turned out to be the most robust in a previous study of Arias-Rodil et al. (2015b).

\section{Model formulation}

\subsection{Dynamic systems}

A forest growth model predicts future values of certain outputs (e.g. timber volume) given inputs (e.g. type, intensity, and timing of thinning), both of which are functions of time. The state-space approach (Zadeh and Polak, 1969) was first used in forestry by García (1994), and has become a common approach for modelling forest dynamic systems (e.g. Diéguez-Aranda et al., 2006; Castedo-Dorado et al., 2007). The idea of this approach is to characterize the state of the system at any point in time in such a way that given the present state the future does not depend on the past, i.e. it is assumed that the state information is enough to determine the behaviour of the system from that time on. This state is defined by a vector of variables, and it is then assumed that two stands with the same values for these variables will behave equally regardless of how they reached that state.

As silvicultural treatments generally occur at specific times and cause instant changes in the state, we can assume that the inputs (system control variables) are given by a vector $\tilde{\mathbf{u}}$, and we denote by $\mathbf{x}(t)$ the finite-dimensional vector of the system state, and by $\mathbf{y}(t)$ the finitedimensional vector of the system outputs. The behaviour of the system is then characterised by two functions:

1. A transition function $\mathbf{F}$

$$
\mathbf{x}(t)=\mathbf{F}\left[\mathbf{x}\left(t_{0}\right), \tilde{\mathbf{u}}, t-t_{0}\right], \quad \forall t \geq 0,
$$

2. An output function $\mathbf{g}$

$$
\mathbf{y}(t)=\mathbf{g}[\mathbf{x}(t)], \quad \forall t \geq 0 .
$$


Function $\mathbf{F}$ gives the current state $(\mathbf{x}(t))$ as a function of the initial state $\left(\mathbf{x}\left(t_{0}\right)\right)$, the system control variables $(\tilde{\mathbf{u}})$, and the elapsed time between the initial time $\left(t_{0}\right)$ and the current time $(t)$. The transition function can be obtained, in many cases, by solving the system of differential equations which describe the rate of change of the state variables. Function $\mathbf{g}$ gives the current value of any other variable of interest $(\mathbf{y}(t))$ as a function of the current state $(\mathbf{x}(t))$.

Both the transition and output functions are frequently used in forest growth and yield modelling. In section 2.2 we present a general dynamic model for the growth of pure, even-aged stands. We will show how, in this case, the transition and output functions are differentiable with respect to the decision variables. Moreover, from a given initial condition, we will give an explicit expression of the system outputs in terms of the decision variables, which is very useful to calculate its derivatives when seeking the optimal management of a stand.

\subsection{Dynamic growth model for single-species, even-aged stands}

According to García (1994), for single-species, even-aged stands in which a wide range of silvicultural treatments (various thinning regimes and initial spacings) may be applied (except heavy thinning and pruning) and for which we are interested in volumes of various products and parameters of size distributions, the state of a stand can be sufficiently described using the following variables: dominant height $(H(t)$, defined as the mean height of the dominant trees), number of stems per unit of land area $(N(t))$, and stand basal area $(G(t)$, defined as the total cross-sectional area of all stems in a stand measured at breast height, and expressed as per unit of land area); following the notation introduced in section 2.1, $\mathbf{x}(t)=(H(t), N(t), G(t))$. In this model, the state variables are given by known functions, $h, n, g: \mathbb{R}^{+} \times \mathbb{R}^{+} \times \mathbb{R}^{+} \longrightarrow \mathbb{R}$, so that, if for any $\bar{t} \in[a, b]$ we know the values of $H(\bar{t})=\bar{H}, N(\bar{t})=\bar{N}$, and $G(\bar{t})=\bar{G}$ and no treatment 
is applied in the stand during that time interval, it is verified that, for all $t \in[a, b]$,

$$
\begin{aligned}
H(t) & =h(\bar{t}, \bar{H}, t), \\
N(t) & =n(\bar{t}, \bar{N}, t), \\
G(t) & =g(\bar{t}, \bar{G}, t) .
\end{aligned}
$$

Functions $h, n$, and $g$ are often smooth (usually $h, n, g \in C^{\infty}\left(\mathbb{R}^{+} \times \mathbb{R}^{+} \times \mathbb{R}^{+}\right)$) and, obviously, functions $H, N$, and $G$ have the same smooth properties in $[a, b]$.

Moreover, as we have already indicated, from these functions we can estimate any other variable of interest (output) of the problem. For example, to estimate the merchantable stem volume to any top diameter limit $d>0$, we have other function $v \in C^{\infty}\left(\mathbb{R}^{+} \times \mathbb{R}^{+} \times \mathbb{R}^{+} \times \mathbb{R}^{+}\right)$ such that, if $V^{d}(t)$ denotes the merchantable stand volume of diameter greater than $d$ at time $t$, then

$$
V^{d}(t)=v(H(t), N(t), G(t), d), \quad t \geq 0
$$

Let consider now an initial stand of age $t_{0}$, with state variables $H_{0}, N_{0}$, and $G_{0}$, in which a first thinning is done in instant $t_{1}>t_{0}$, of intensity (proportion of stems to remove) $I_{1} \in(0,1)$ and type of thinning defined as a removal relation (variable that relates the number of stems and the stand basal area removed and before thinning) $R_{1} \in(0,1]$ (Álvarez González et al., 1999). This causes that functions $N$ and $G$ (not $H$, since it is assumed not affected by thinning as no dominant trees are removed) suffer a jump discontinuity at that instant, verifying that

$$
\begin{aligned}
& H\left(t_{1}^{+}\right)=H\left(t_{1}^{-}\right)=H\left(t_{1}\right), \\
& N\left(t_{1}^{+}\right)=\left(1-I_{1}\right) N\left(t_{1}^{-}\right), \\
& G\left(t_{1}^{+}\right)=\left(1-I_{1} R_{1}\right) G\left(t_{1}^{-}\right),
\end{aligned}
$$

where $H\left(t_{1}^{+}\right), N\left(t_{1}^{+}\right)$, and $G\left(t_{1}^{+}\right)$are the values of the functions after thinning and $H\left(t_{1}^{-}\right), N\left(t_{1}^{-}\right)$, and $G\left(t_{1}^{-}\right)$the values before thinning. 
Therefore, if no further thinning is carried out in the stand until time $t_{2}>t_{1}$, combining (4)-(5) with (7)-(8) we have that, for all $t \in\left[t_{1}, t_{2}\right]$,

$$
\begin{aligned}
& N(t)=n\left(t_{1}, N\left(t_{1}^{+}\right), t\right)=n\left(t_{1},\left(1-I_{1}\right) N\left(t_{1}^{-}\right), t\right)=n\left(t_{1},\left(1-I_{1}\right) n\left(t_{0}, N_{0}, t_{1}\right), t\right), \\
& G(t)=g\left(t_{1}, G\left(t_{1}^{+}\right), t\right)=g\left(t_{1},\left(1-I_{1} R_{1}\right) G\left(t_{1}^{-}\right), t\right)=g\left(t_{1},\left(1-I_{1} R_{1}\right) g\left(t_{0}, G_{0}, t_{1}\right), t\right) .
\end{aligned}
$$

It should be noted that, although functions $N(t)$ and $G(t)$ are not continuous in $\left[0, t_{2}\right]$ (they have a jump discontinuity in $\left.t_{1}\right)$, functions ${ }^{1}$

$$
\begin{aligned}
& H(t)=h\left(t_{0}, H_{0}, t\right), \quad t \in \mathbb{R}^{+}, \\
& N_{0}(t)=n\left(t_{0}, N_{0}, t\right), \quad t \in D_{0}, \\
& N_{1}\left(t_{1}, I_{1}, t\right)=n\left(t_{1},\left(1-I_{1}\right) n\left(t_{0}, N_{0}, t_{1}\right), t\right), \quad\left(t_{1}, I_{1}, R_{1}, t\right) \in D_{1}, \\
& G_{0}(t)=g\left(t_{0}, G_{0}, t\right), \quad t \in D_{0}, \\
& G_{1}\left(t_{1}, I_{1}, R_{1}, t\right)=g\left(t_{1},\left(1-I_{1} R_{1}\right) g\left(t_{0}, G_{0}, t_{1}\right), t\right), \quad\left(t_{1}, I_{1}, R_{1}, t\right) \in D_{1},
\end{aligned}
$$

have the same smooth properties as $h, n$, and $g$ in their respective domains: $D_{0}=\{t \in \mathbb{R}, t \geq 0\}$, $D_{1}=\left\{\left(t_{1}, I_{1}, R_{1}, t\right) \in \mathbb{R}^{4}, t \geq t_{1} \geq 0, I_{1} \in(0,1), R_{1} \in(0,1]\right\}$.

It is essential to note that this type of functions are those required in managing a stand: $H(t)$ provides the dominant height at any instant $t>0, N_{0}(t)$ and $G_{0}(t)$ give the number of stems and the stand basal area until the first thinning, and $N_{1}\left(t_{1}, I_{1}, t\right)$ and $G_{1}\left(t_{1}, I_{1}, R_{1}, t\right)$ provide the number of stems and the stand basal area from the first thinning $\left(t \geq t_{1}\right)$, but considering that the first thinning was done in instant $t_{1}$, with an intensity $I_{1}$ and a type of thinning given by $R_{1}$.

This type of functions constitute the transition function of the model $(\mathbf{F})$, for which we can give an explicit expression. For example, if only one thinning is going to be applied, then

\footnotetext{
${ }^{1}$ For simplicity, we will use the same notation for the function $N_{0}(t)$ (respectively $G_{0}(t)$ ) and the initial state variable $N_{0}$ (respectively $G_{0}$ ).
} 
$\tilde{\mathbf{u}}=\left(t_{1}, I_{1}, R_{1}\right)$ and

$$
\mathbf{x}(t)=\mathbf{F}\left[\mathbf{x}\left(t_{0}\right), \tilde{\mathbf{u}}, t-t_{0}\right]= \begin{cases}\left(H(t), N_{0}(t), G_{0}(t)\right) & \text { if } t<t_{1} \\ \left(H(t), N_{1}\left(t_{1}, I_{1}, t\right), G_{1}\left(t_{1}, I_{1}, R_{1}, t\right)\right) & \text { if } t \geq t_{1}\end{cases}
$$

Remark 1. Generically, the volume removed in the $i^{\text {th }}$ thinning will be:

$$
\begin{aligned}
& V_{i}^{r, d}\left(t_{1}, I_{1}, R_{1}, \ldots, t_{i}, I_{i}, R_{i}\right)= \\
& \quad V_{i-1}^{d}\left(t_{1}, I_{1}, R_{1} \ldots, t_{i-1}, I_{i-1}, R_{i-1}, t_{i}\right)-V_{i}^{d}\left(t_{1}, I_{1}, R_{1} \ldots, t_{i}, I_{i}, R_{i}, t_{i}\right)
\end{aligned}
$$


being the $V_{i}^{d}$ functions given, in analogy to (18), as

$$
\begin{aligned}
& V_{i}^{d}\left(t_{1}, I_{1}, R_{1}, \ldots, t_{i}, I_{i}, R_{i}, t\right)= \\
& \quad v\left(H(t), N_{i}\left(t_{1}, I_{1}, \ldots, t_{i}, I_{i}, t\right), G_{i}\left(t_{1}, I_{1}, R_{1}, \ldots, t_{i}, I_{i}, R_{i}, t\right), d\right),
\end{aligned}
$$

where, in turn, $N_{i}$ and $G_{i}$ are given, as in (13) and (15), by the recurring formula

$$
\begin{aligned}
& N_{i}\left(t_{1}, I_{1}, \ldots, t_{i}, I_{i}, t\right)=n\left(t_{i},\left(1-I_{i}\right) N_{i-1}\left(t_{1}, I_{1}, \ldots, t_{i-1}, I_{i-1}, t_{i}\right), t\right) \\
& G_{i}\left(t_{1}, I_{1}, R_{1}, \ldots, t_{i}, I_{i}, R_{i}, t\right)=g\left(t_{i},\left(1-I_{i} R_{i}\right) G_{i-1}\left(t_{1}, I_{1}, R_{1}, \ldots, t_{i-1}, I_{i-1}, R_{i-1}, t_{i}\right), t\right) .
\end{aligned}
$$

As defined, it is evident that all functions $N_{i}$ and $G_{i}$ have the same smoothness as $n$ and $g$ respectively. Moreover, by asumming that $v \in C^{\infty}\left(\mathbb{R}^{+} \times \mathbb{R}^{+} \times \mathbb{R}^{+} \times \mathbb{R}^{+}\right)$, that smoothness with the smoothness of $h$, determine the smoothness of all functions $V_{i}^{d}$ and $V_{i}^{r, d}$.

\subsection{Optimal stand management}

The optimal management of a stand implies selecting the silvicultural prescription that maximizes the specified objective function (e.g. mean annual volume increment, soil expectation value). For that purpose, we search the number of thinnings that must be applied $\left(n_{t} \in \mathbb{N} \cup\{0\}\right)$, the timing $\left(t_{i} \geq 0, i=1, \ldots, n_{t}\right)$ of each thinning, its intensity $\left(I_{i} \in(0,1), i=1, \ldots, n_{t}\right)$ and type (defined by its removal relation $\left.R_{i} \in(0,1], i=1, \ldots, n_{t}\right)$, and finally the timing of clearcutting $\left(t_{n_{t+1}} \geq 0\right)$. Technologic, logistic or economic restrictions limit the possible number of thinnings and, therefore, considering that $n_{t}$ must be a small number (generally lower than 5 ), we can eliminate it from the decision variable and maximize the objective function for each value of $n_{t}$ accepted (instead of one problem we will have to solve several, but in all of them $n_{t}$ will be a given value).

Thus, once set the value of $n_{t}$, the vector of decision variables of the problem is $\mathbf{u}=\left(t_{1}, I_{1}, R_{1}, \ldots, t_{n_{t}}, I_{n_{t}}, R_{n_{t}}, t_{n_{t}+1}\right) \in \mathbb{R}^{3 n_{t}+1}$. The logistic and economic restrictions mentioned also determine minimum time intervals until the first thinning $\left(l_{1}>0\right)$, between thinning 
$i$ and thinning $i+1\left(l_{i}>0\right)$, and between the last thinning and the clearcutting $\left(l_{n_{t}+1}>0\right)$. In addition, there are lower $\left(\underline{I}_{i} \in(0,1), \underline{R}_{i} \in(0,1]\right)$ and upper $\left(\bar{I}_{i} \in\left[\underline{I}_{i}, 1\right), \bar{R}_{i} \in\left[\underline{R}_{i}, 1\right]\right)$ bounds for the intensities and removal relations of each thinning, and upper bound for the clearcutting age $(T>0)$. With all of this, the set of allowable actions is given by

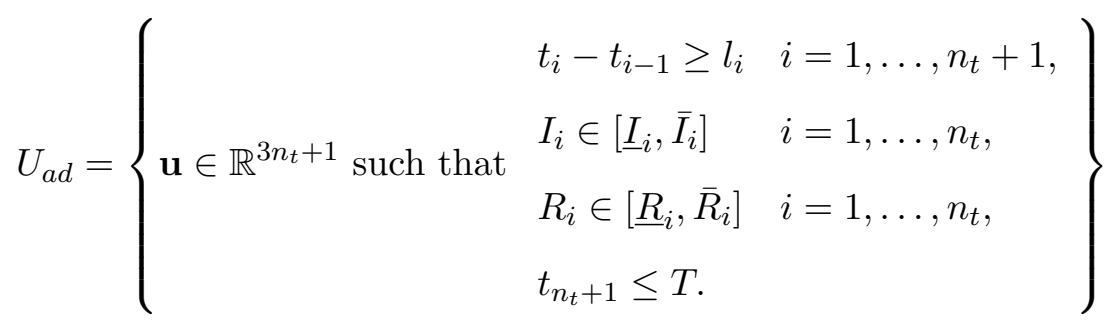

which results closed, bounded, and convex.

The optimal stand management is to solve, for all possible values of $n_{t}$, the problem

$$
\max _{\mathbf{u} \in U_{a d}} J(\mathbf{u}),
$$

where $J(\mathbf{u})$ is the objective function of the stand, defined from functions $\mathbf{F}$ and $\mathbf{g}$. In the next section we detail, as an example, a typical function $J$ for optimizing the management of single-species, even-aged stands from an economic perspective.

\subsection{Optimal stand management from an economic perspective}

To optimize the management of a forest stand from an economic perspective, the criterion generally used is the soil expectation value (SEV, money per unit area) of all future net revenues from wood production, which enables comparison of management schedules involving different rotations lengths as it assumes that the revenues are reinvested (Bettinger et al., 2009, p. 41):

$$
J(\mathbf{u})=\frac{R(\mathbf{u})-C(\mathbf{u})}{1-\frac{1}{(1+r)^{t_{N_{t}+1}}}},
$$


where $R(\mathbf{u})$ and $C(\mathbf{u})$ are, respectively, present values of revenues and management costs, and $r \in[0, \infty)$ is a pre-specified known annual discount rate. For single-species, even-aged stands, functions $R(\mathbf{u})$ and $C(\mathbf{u})$ are given by elementary operations between $H$, given by (3), and functions $V_{i}^{d}, N_{i}$, and $G_{i}$, given by (21)-(23). In the next two sections we detail typical expressions for functions $R$ and $C$.

\subsubsection{Revenues}

For $i=1, \ldots, n_{t}$, funtions $V_{i}^{r, d}\left(t_{1}, I_{1}, R_{1}, \ldots, t_{i}, I_{i}, R_{i}\right)$, given by $(20)$, provide an estimate of the removed stand volume to a specified top diameter limit in the $i^{\text {th }}$ thinning. In a similar way,

$$
V_{n_{t}+1}^{r, d}(\mathbf{u})=V_{n_{t}}^{d}(\mathbf{u})
$$

provides an estimate of the same top diameter limit volume at the rotation age $\left(t=t_{n_{t}+1}\right)$. The revenues will be obtained by multiplying the volume by size assortments times its corresponding expected price.

In general, the following $n_{a} \in \mathbb{N}$ size assortments are considered:

- Type 1: stand volume with top diameter limit less than $d_{1}>0$, with a price $p_{1}$.

- Type $j$ (with $j=2, \ldots, n_{a}-1$ ): stand volume with diameter between $d_{j}$ and $d_{j-1}$, with a price $p_{j}$

- Type $n_{a}$ : stand volume with top diameter limit larger than $d_{n_{a}-1}$, with a price $p_{n_{a}}$.

If we define $d_{0}=0$ and $p_{0}=0$, the revenues obtained at each harvest $i$, for $i=1, \ldots, n_{t+1}$, will be

$$
\sum_{j=1}^{n_{a}}\left(p_{j}-p_{j-1}\right) V_{i}^{r, d_{j-1}}\left(t_{1}, I_{1}, \ldots, t_{i}, I_{i}\right)
$$


Finally, the present value of those revenues for an $r \in[0,1]$ annual discount rate will be

$$
R(\mathbf{u})=\sum_{i=1}^{n_{t}+1} \frac{1}{(1+r)^{t_{i}}}\left(\sum_{j=1}^{n_{a}}\left(p_{j}-p_{j-1}\right) V_{i}^{r, d_{j-1}}\left(t_{1}, I_{1}, \ldots, t_{i}, I_{i}\right)\right)
$$

\subsubsection{Costs}

Stand management implies several cost types:

1. Plantation and maintenance costs before the first thinning: they are a function of plantation density and the number of trees at the time $\left(0<t_{0}^{1}<\ldots<t_{0}^{c_{0}}<t_{0}+l_{1}\right)$ of each action (i.e. management treatment). They do not depend on the decision variable of the problem and, for a given stand, are denoted by a constant

$$
C_{\text {plan }+ \text { main }}=f_{p}\left(N_{0}(0)\right)+\frac{f_{r m}\left(N_{0}(0)\right)}{(1+r)^{t_{r m}}}+\sum_{k=1}^{c_{0}} \frac{f_{0}^{k}\left(N_{0}\left(t_{0}^{k}\right)\right)}{(1+r)^{t_{0}^{k}}} .
$$

where $f_{p}$ is the plantation cost, $f_{r m}$ is the replanting and management cost of the $t_{r m}$ year, $c_{0}$ is the number of planned actions in time interval $\left(0, t_{0}+l_{1}\right)$, and functions $f_{0}^{k}(N)$ provide the cost of the $k^{t h}$ action which is done before the first thinning.

2. Maintenance costs between cuttings: as for the maintenance before the first thinning, these costs are a function of the number of trees at the time when each action (scrub clearance, low pruning...) is applied. We admit that these actions are done always between the same cuttings and, for example, if between cutting $i$ and cutting $i+1$ two actions are planned, we denote by $\delta_{i}^{1}, \delta_{i}^{2}$ the elapsed time between thinning $i$ and each of the two actions $\left(0<\delta_{i}^{1}<\delta_{i}^{2}<\left(l_{i+1}\right)\right)$. In response to this, maintenance costs between cuttings will be

$$
C_{\text {main }}(\mathbf{u})=\sum_{i=1}^{n_{t}} \sum_{k=1}^{c_{i}} \frac{f_{i}^{k}\left(N_{i}\left(t_{1}, I_{1}, \ldots, t_{i}, I_{i}, t_{i}+\delta_{i}^{k}\right)\right)}{(1+r)^{t_{i}+\delta_{i}^{k}}}
$$

where $c_{i}$ is the number of planned actions in time interval $\left(t_{i}, t_{i+1}\right)$. Functions $f_{i}^{k}(N)$ provide the cost of the $k^{\text {th }}$ action which is done in period $\left(t_{i}, t_{i+1}\right)$. It is evident that, if $n$ 
is sufficiently smooth, the smoothness of $C_{\text {main }}(\mathbf{u})$ is given by the smoothness of functions $f_{i}^{k}(N)$. Nevertheless, it should be noted that, if actions are done at fixed times which may vary between thinnings, function $C_{\text {main }}(\mathbf{u})$ may present discontinuities.

3. High pruning costs: they are given as a function $(q(N))$ of the expected number of trees at rotation age. Therefore, if high pruning is done only once at time $t_{h p}$, the corresponding costs will be of the form

$$
C_{h p}(\mathbf{u})=\frac{q\left(N_{n_{t}}(\mathbf{u})\right)}{(1+r)^{t_{h p}}} .
$$

4. Harvesting costs: all thinnings and the clearcutting involve costs associated with the cut and extraction of the timber which are a function of the number of trees before cutting, the extracted volume, and also of the average size of the trees removed. The last variable may be represented by its quadratic mean diameter $\left(D_{g}^{r}\right)$, which is obtained directly from the removed number of trees $N^{r}$ and stand basal area $G^{r}$ through the expression

$$
D_{g}^{r}=\sqrt{\frac{40000 G^{r}}{N^{r} \pi}}
$$

Therefore, harvesting costs are of the form

$$
\begin{aligned}
C_{\text {harv }}(\mathbf{u})= & \frac{s_{n_{t}+1}\left(N_{n_{t}}(\mathbf{u}), G_{n_{t}}(\mathbf{u}), V_{n_{t}}^{0}(\mathbf{u})\right)}{(1+r)^{t_{n_{t}+1}}}+ \\
\sum_{i=1}^{n_{t}} & \frac{1}{(1+r)^{t}} s_{i}\left(N_{i-1}\left(t_{1}, I_{1}, \ldots, t_{i-1}, I_{i-1}, t_{i}\right), N_{i}\left(t_{1}, I_{1}, \ldots, t_{i}, I_{i}, t_{i}\right),\right. \\
& G_{i-1}\left(t_{1}, I_{1}, R_{1}, \ldots, t_{i-1}, I_{i-1}, R_{i-1}, t_{i}\right), G_{i}\left(t_{1}, I_{1}, R_{1}, \ldots, t_{i}, I_{i}, R_{i}, t_{i}\right), \\
& \left.V_{i}^{r, 0}\left(t_{1}, I_{1}, \ldots, t_{i}, I_{i}\right)\right),
\end{aligned}
$$

where functions $s_{i}(N)$ are those of harvesting cost $i$.

Finally, the function of total management costs of the stand will be

$$
C(\mathbf{u})=C_{\text {plan }+ \text { main }}+C_{\text {main }}(\mathbf{u})+C_{h p}(\mathbf{u})+C_{\text {harv }}(\mathbf{u}) .
$$




\subsubsection{Analysis and numerical resolution}

We assume that $h, n, g$, and $v$ are sufficiently smooth (i.e. class $C^{\infty}$ ). As stated, functions $H$, $N_{i}, G_{i}, V_{i}^{d}$, and $V_{i}^{r, d}$ are class $C^{\infty}$ and, consequently, function $R$, given by (29), is also $C^{\infty}$. The smoothness of $C$, given by (35), is given by the smoothness of functions $f_{i}^{k}, q$, and $s_{i}$. For example, if these functions are class $C^{\infty}$, then $C$, and therefore $J$, given by (26), are class $C^{\infty}$. In this situation, as $U_{a d}$ (equation (24)) is closed and bounded, the continuity of $J$ guarantees the existence of a solution for problem (25). Moreover, because $U_{a d}$ is convex, the uniqueness of solution would be also guaranteed if, for example, $J$ is strictly concave.

On the other hand, the differentiability of functions $f_{i}^{k}, q$, and $s_{i}$ is enough to guarantee the differentiability of the objective function $J$. In this case, problem (25) can be solved by any derivative-based optimization method (see, for example Nocedal and Wright, 2006, for a detailed presentation of these methods). The gradient of the objective function $(\nabla J)$ can be easily obtained by simply using the chain rule, but the calculations can be very tedious if the involved functions are not simple enough. In those cases, a finite difference method (see, for example Nocedal and Wright, 2006, chapter 8) can be useful to approximate $\nabla J(\mathbf{u})$, whenever necessary. As an example, in section 3 we numerically solve problem (25) for a particular case.

\section{Case study: Optimization of the management of Pinus pinaster} Ait. in Asturias (NW Spain) from an economic perspective

A dynamic growth model has recently been developed for pure, even-aged stands of maritime pine (Pinus pinaster Ait.) in Asturias (NW Spain) (see Arias-Rodil et al., 2015a, for details), where it is one of the most important timber species, occupying 22500 ha (almost $5 \%$ of the total forest area, MAGRAMA, 2012). The joint use of the model (properly implemented in a computer program to simulate thinning treatments) and an optimization algorithm allowed to select the best silvicultural prescriptions at stand level for managing the species in the region from an economic perspective (Arias-Rodil et al., 2015b). These authors evaluated six optimiza- 
tion methods: depth-first search (DFS, see Russell and Norvig, 2009, p. 85) and five direct search methods (Hooke and Jeeves method -1961, HJ- and four population-based methods, including differential evolution -DE, Storn and Price, 1997). According to their results, after several optimization runs for various example stands (differing in site quality and plantation density), HJ yielded the highest value of the objective function in most cases and was the fastest method, although DE behaved similar and was more stable. Therefore, in this section we used the HJ and DE methods as reference to compare with our approach in stand-level optimization of economic benefit.

\subsection{Simulation of stand dynamics}

The dynamic stand growth model for Pinus pinaster in Asturias represents an example of the model explained in section 2.2 in which model functions are (see Arias-Rodil et al., 2015a, for details):

$$
\begin{aligned}
& h(\bar{t}, \bar{H}, t)=\frac{41.40}{1-\left(1-\frac{41.40}{\bar{H}}\right)\left(\frac{\bar{t}}{t}\right)^{1.325}}, \\
& n(\bar{t}, \bar{N}, t)=\bar{N} e^{-4.29610^{-3}(t-\bar{t})}, \\
& g(\bar{t}, \bar{G}, t)=\frac{\frac{1}{2}\left(\bar{G}+\sqrt{\bar{G}^{2}+880468 \bar{G} \bar{t}^{-2.255}}\right)}{1+\frac{220117}{\frac{1}{2}\left(\bar{G}+\sqrt{\bar{G}^{2}+880468 \bar{G}^{-2.255}}\right)} t^{-2.255}}, \\
& v(H, N, G, d)=0.6677 G^{0.9789} H^{0.8440} e^{-0.3427\left(\sqrt{\frac{40000 G}{N \pi}}\right)^{-2.949} d^{3.313}} .
\end{aligned}
$$

In this model, each stand is characterized by its site index $(S$, defined as the dominant height of the stand at a reference age of 20 years) or its dominant height $H_{0}$ at any moment $t_{0}>0$, 
and by the number of trees $N_{0}$ at $t_{0}$. From these values, $H_{0}$ (if needed) and $G_{0}$ (if it is not calculated from inventory data) are obtained in the following manner:

$$
\begin{aligned}
& H_{0}=h\left(20, S, t_{0}\right), \\
& G_{0}=0.005790 S^{1.030} N_{0}^{0.3971} t_{0}^{1.057} .
\end{aligned}
$$

\subsection{Optimal stand management}

\subsubsection{Decision variables}

In the present case study, the decision variable indicated in section 2.3 included the rotation age $t_{n_{t+1}}$ and the timing $t_{i}$ and intensity $I_{i}$ of thinnings. The maximum number of thinning operations considered was three $\left(n_{t} \leq 3\right)$, given that only 1-2 are usually applied in Asturias (Rodríguez et al., 2007, p. 44). The removal relation $R_{i}$, in this case defined as $R_{i}=\frac{G_{r} / G_{b t}}{N_{r} / N_{b t}}$ (Álvarez González et al., 1999), relates the number of stems and the stand basal area removed $\left(N_{r}\right.$ and $\left.G_{r}\right)$ and before thinning $\left(N_{b t}\right.$ and $\left.G_{b t}\right)$. It was dropped from the decision variable to simplify the analysis of results. Therefore, it was fixed to a value of 0.9 for the first thinning, which represents a a combination of uniform and low thinning, and to 0.75 for subsequent thinnings, which describe an intermediate thinning (a combination of low and crown thinning), respectively (Kerr and Haufe, 2011, pp. 20-23).

In this case, the vector of decision variables of the problem results $\mathbf{u}=\left(t_{1}, I_{1}, \ldots, t_{n_{t}}, I_{n_{t}}, t_{n_{t}+1}\right) \in \mathbb{R}^{2 n_{t}+1}$, for $n_{t}=0,1,2,3$.

\subsubsection{Constraints}

As stated in section 2.3, based on the study of Arias-Rodil et al. (2015b) several restrictions were considered in the optimization process:

- Minimum thinning intensity of $15 \%\left(\underline{I}_{i}=0.15\right)$, because of logistic and economic considerations. 
- Maximum thinning intensity of $45 \%\left(\bar{I}_{i}=0.45\right)$, to prevent the stand from becoming too sensitive to wind throw or snow breakage (Castedo-Dorado, 2009).

- Minimum interval between consecutive cuttings of $l_{i}=5$ years, to prevent too-frequent cutting, which may harm the residual stand due to damage arising from the use of harvesters or forwarders (Han and Kellogg, 2000). This constraint is also related to both wind and, in the interval between consecutive thinning operations, snow protection and residual stand damage (Arias-Rodil et al., 2015b).

- Maximum rotation age of $T=100$ years, because of model limitations (Arias-Rodil et al., 2015b).

\subsubsection{Objective function: soil expectation value}

Selection of the best management prescription from an economic perspective consists of maximizing function $J$ given by (26). Next, we detail the revenues and costs associated with this case study. The interest rate was set to $4 \%$.

Revenues The timber assortments considered in the present study and their roadside prices are a simplification of those used by Arias-Rodil et al. (2015b) (here we did not consider the requirement of log length -see Table 1), which were defined after consulting various forest associations and timber companies of Asturias and nearby regions (three timber assortments, $n_{a}=3$, with the following distribution: $d_{1}=15, p_{1}=25, d_{2}=40, p_{2}=40, p_{3}=60$ ).

[Table 1 about here.]

Costs The following cost functions ( $\left.€ \mathrm{ha}^{-1}\right)$ used by Arias-Rodil et al. (2015b) were considered (all but functions $c(N), \lambda_{1}(N), \lambda_{2}(N), \mu_{1}(N)$, and $\mu_{2}(N)$, which were made smooth to avoid discontinuities): 
1. Plantation and maintenance before the first thinning: $c_{0}=2$,

$$
\begin{aligned}
& f_{p}(N)=604.1+43.93 \sqrt{\frac{N}{100}}+1.134 N\left(\text { plantation }, t_{p}=0\right), \\
& f_{r m}(N)=150+0.217 N\left(\text { replanting and scrub clearance, } t_{r m}=1\right), \\
& f_{0}^{1}(N)=0.217 N\left(\text { scrub clearance, } t_{0}^{1}=2\right), \\
& f_{0}^{2}(N)=949.9+0.5268 N\left(\text { scrub clearance and low pruning, } t_{0}^{2}=12\right) .
\end{aligned}
$$

where:

$$
\begin{aligned}
& s_{i}\left(N_{i-1}, N_{i}, G_{i-1}, G_{i}, V_{i}^{r, 0}\right)=223.2+c\left(D_{g, i}^{r}\right) V_{i}^{r, 0}+ \\
& 1.538\left(N_{i-1}-N_{i}\right)\left(1.182+\lambda_{1}\left(D_{g, i}^{r}\right)+\lambda_{2}\left(N_{i-1}\right)+\lambda_{3}\left(N_{i-1}-N_{i}\right)\right),
\end{aligned}
$$


(b) Clearcutting

$$
\begin{aligned}
& s_{n_{t}+1}\left(N_{n_{t}}, G_{n_{t}}, V_{n_{t}}^{0}\right)=223.2+c\left(D_{g}^{n_{t}+1}\right) V_{n_{t}}^{0}+ \\
& 2.548 N_{n_{t}}\left(1.106+\mu_{1}\left(D_{g}^{n_{t}+1}\right)+\mu_{2}\left(N_{n_{t}}\right)+\mu_{3}\left(N_{n_{t}}\right)\right),
\end{aligned}
$$

where:

$$
\begin{aligned}
& D_{g}^{n_{t}+1} \equiv D_{g}^{n_{t}+1}\left(N_{n_{t}}, G_{n_{t}}\right)=\sqrt{\frac{40000 G_{n_{t}}}{\pi N_{n_{t}}}} \\
& \mu_{1}(D)=0.07 D^{0.54} \\
& \mu_{2}(N)=1.910^{-4} N^{0.87} \\
& \mu_{3}(N)=-0.02124+55.51 \log (N)^{-4.161} .
\end{aligned}
$$

\subsubsection{Numerical resolution}

Considering that all model functions are smooth, we propose the use of a gradient-based method to solve problem (25). To be exact, we used a Sequential Quadratic Programming (SQP) algorithm, which is detailed in Nocedal and Wright (2006, chapter 18). The gradient, when necessary, was approximated by the forward-finite-difference method (see, e.g. chapter 8 in Nocedal and Wright, 2006). For comparison, we also solved the problem with the direct-search methods HJ and DE, treating the constraints with a penalty function.

The model proposed in this case study differs from that of Arias-Rodil et al. (2015b) in two aspects:

- The way in which thinning treatments were simulated. In the previous study, the first thinning was considered to be a combination of uniform and low thinning (applying the latter over the remaining trees after the former), while the subsequent thinning operations were assumed to be entirely from below. Uniform thinning was simulated by removing the same proportion of trees from each diameter class, while the low thinning operations were simulated following the approach proposed by Alder (1979). In this study, the simulation 
of stand basal area removed was done using a fixed removal relation of 0.9 for the first thinning (which describes a combination of uniform and low thinning) and of 0.75 for subsequent thinnings (which is indicative of intermediate thinning).

- Functions $c(N), \lambda_{1}(N), \lambda_{2}(N), \mu_{1}(N)$, and $\mu_{2}(N)$ used in the computation of the cutting costs. The previous formulation of these functions involved artificial discontinuities that were avoided by fitting a smooth function.

Therefore, our results are not directly comparable with those of Arias-Rodil et al. (2015b). Nevertheless, the interest of this study is to show how the new formulation of the model is more appropriate in optimization.

\section{$3.3 \quad$ Numerical results}

We tested the three approaches (SQP, HJ, and DE) using 16 example stands which differ in site index ( $S$, the dominant height expected at a reference age of 20 years) and number of stems per hectare at plantation. The optimal results are shown in table 2 .

[Table 2 about here.]

Concerning the optimal value of the objective function, SQP and HJ provided the same results, while DE always yielded lower values $(0.44 \%$ worse on average, with a coefficient of variation of 38.1\%). This finding disagrees with other studies like Pukkala (2009), where DE provided the best results for maximization of the net present value of 719 stands in North Karelia (Finland). Additionally, SQP and HJ were robust and always provided the same optimal value when repeating the optimization process from different starting values, while DE showed variability (the coefficient of variation of the optimal results for each example stand after 20 optimization runs ranged from $0.05 \%$ to $0.41 \%$ ). When comparing optimization techniques, it becomes of special interest their evaluation in terms of efficiency, as they could be implemented in decision support systems, where this characteristic becomes valuable. For this, using the number of function evaluations allows a fair comparison avoiding the effect of computer capabilities or 
programmer skills (Talbi, 2009, p. 62). In terms of number of function evaluations, SQP was 3.1 and 20.6 times more efficient on average across the best solutions for all example stands (coefficients of variation of $14.5 \%$ and $22.9 \%$ ) than HJ and DE, respectively. It corresponds to a higher difference in CPU time used because $\mathrm{HJ}$ and DE algorithms include a penalty function with several 'if' control structures that slow down the optimization process (we do not provide times of this comparison because of its dependence on machine and programming skills).

Arias-Rodil et al. (2015b) reported that HJ method got sometimes trapped to a local optimum, which was also found by Pukkala (2009) for some stands when optimizing the net present value of the mentioned forest of 719 stands. However, when Pukkala (2009) optimized the net present value of an example stand, the HJ method proved stable. In this study, HJ method always led to the same management prescription when repeating the optimization process. This is probably because the model proposed in this study differs from that of Arias-Rodil et al. (2015b) in functions $c(N), \lambda_{1}(N), \lambda_{2}(N), \mu_{1}(N)$, and $\mu_{2}(N)$ involved in the computation of the harvesting costs. These functions are now smooth, which avoids the artificial discontinuities that might make the algorithms stopping in local maxima.

Table 2 also indicates the number of thinnings of the optimal silvicultural prescription that maximizes the SEV. The general trend of the optimal prescription implies to carry out thinnings of the highest intensity allowed (45\%) and cuttings at the minimum time interval (5 years, except in the three example stands of lower quality $-S=7 \mathrm{~m}-$ and higher density $-N_{0}=900,1300$, 1700 trees $\mathrm{ha}^{-1}$ - in which the clearcutting is delayed $2.5,6.5$, and 11.2 years, respectively). Considering these results, it is possible to analyze the behaviour of the objective function if we fix all but two decision variables to the allowable upper and lower bounds indicated and evaluate how the objective function value varies with the value of the decision variables maintained free. For example, figure 1 shows the graph of function $J\left(t_{1}, I_{1}, t_{1}+5,0.45, t_{1}+10,0.45, t_{1}+15\right)$, which corresponds to the SEV when we only vary the timing $\left(t_{1}\right)$ and intensity $\left(I_{1}\right)$ of the first thinning for the example stand of site index $S=13 \mathrm{~m}$ and number of trees per hectare at plantation $N_{0}=1300$. As can be observed, function $J$ is smooth for the two free variables and 
[Figure 1 about here.]

\section{Conclusions}

In this study we propose a linearly constrained smooth optimization model formulation to optimize the management of single-species, even-aged stands. We exemplify this formulation for a case study of maximization of the economic profitability of Pinus pinaster Ait. in Asturias at stand level, solving it using a derivative-based algorithm. It is noteworthy that:

1. Whenever possible, it is advisable to use smooth models, mainly for two reasons:

(a) They are easier to solve because:

- Gradient-type methods can be used, which are very efficient and robust.

- Derivative-free methods also behave better (are more robust), as can be seen for the application of the Hooke and Jeeves (1961) method in this study as compared to the study of Arias-Rodil et al. (2015b), where HJ got trapped in local maxima.

(b) The solutions obtained are never singular (small changes in the decision variable will not cause great changes in the objective function).

2. The use of derivative-based methods in this type of models is very advisable. As exemplified, they are robust and much faster than derivative-free methods. Additionally, their 
efficiency with respect to the latter methods increases with the dimension of the decision variable. Therefore, the use of derivative-based methods would help to better solve much bigger convex problems and possibly also other problems where the convexity is not guaranteed (e.g. in optimization at forest-level with multiple stands in which the dimension of the decision variable and the number of objectives may increase considerably).

3. The derivative-based method used in this study (SQP) resulted very efficient to solve this type of problems.

4. The fact that SQP and HJ always provided the same optimal value when repeating the optimization process from different starting values, suggests that problem (25) has a unique solution for the particular case of study.

\section{Acknowledgements}

The first author was in receipt of an FPU grant (AP2012-5337) from the Spanish Ministry of Education. We thank the Association of Companies of Silviculture and Environment of Asturias (ASYMA), Association of Forest Owners of Asturias (PROFOAS), the Asturian Association of Forest, Timber and Furniture Companies (ASMADERA), and the Forest Association of Galicia (AFG) for providing the cost and price data used in the study.

\section{References}

Alder, D. (1979). A distance-independent tree model for exotic conifer plantations in East Africa. For. Sci. 25(1), 59-71.

Álvarez González, J. G., Rodríguez Soalleiro, R., and Vega Alonso, G. (1999). Elaboración de un modelo de crecimiento dinámico para rodales regulares de Pinus pinaster Ait. en Galicia. For. Syst. 8(2), 319-334. 
Álvarez-González, J. G., Zingg, A., and Gadow, K. von (2010). Estimating growth in beech forests: a study based on long term experiments in Switzerland. Ann. For. Sci. 67(3), 307.

Amidon, E. L. and Akin, G. S. (1968). Dynamic programming to determine optimum levels of growing stock. For. Sci. 14(3), 287-291.

Arias-Rodil, M., Barrio-Anta, M., and Diéguez-Aranda, U. (2015a). Developing a dynamic growth model for maritime pine in Asturias (NW Spain): comparison with nearby regions. Ann. For. Sci. 73(2), 297-320.

Arias-Rodil, M., Pukkala, T., González-González, J. M., Barrio-Anta, M., and Diéguez-Aranda, U. (2015b). Use of depth-first search and direct search methods to optimize even-aged stand management: a case study involving maritime pine in Asturias (NW Spain). Can. J. For. Res. 45(10), 1269-1279.

Arimizu, T. (1958). Regulation of the cut by dynamic programming. J. Oper. Res. Soc. Japan $1(4), 175-182$.

Bettinger, P., Boston, K., Siry, J. P., and Grebner, D. L. (2009). Forest management and planning. Amsterdam: Elsevier, 331 pages.

Burkhart, H. E. and Tomé, M. (2012). Modeling forest trees and stands. Berlin: Springer, 472 pages.

Cao, T. (2010). Silvicultural decisions based on simulation-optimization systems. PhD thesis, 47 pages.

Castedo-Dorado, F. (2009). Inclusión de riesgos abióticos en diagramas de manejo de la densidad. Un caso de estudio en masas de Pinus pinaster Ait. $5^{\circ}$ Congr. For. Español. Ávila: Sociedad Española de Ciencias Forestales.

Castedo-Dorado, F., Diéguez-Aranda, U., and Álvarez-González, J. G. (2007). A growth model for Pinus radiata D. Don stands in north-western Spain. Ann. For. Sci. 64(4), 453-465.

Díaz-Balteiro, L. and Rodríguez, L. C. E. (2006). Optimal rotations on Eucalyptus plantations including carbon sequestration-A comparison of results in Brazil and Spain. For. Ecol. Manage. 229(1-3), 247-258. 
Diéguez-Aranda, U., Castedo Dorado, F., Álvarez González, J. G., and Rojo Alboreca, A. (2006). Dynamic growth model for Scots pine (Pinus sylvestris L.) plantations in Galicia (northwestern Spain). Ecol. Modell. 191(2), 225-242.

García, O. (1994). The state-space approach in growth modelling. Can. J. For. Res. 24(9), 18941903.

- (2013). Building a dynamic growth model for trembling aspen in western Canada without age data. Can. J. For. Res. 43(3), 256-265.

García, O., Burkhart, H. E., and Amateis, R. L. (2011). A biologically-consistent stand growth model for loblolly pine in the Piedmont physiographic region, USA. For. Ecol. Manage. 262(11), 2035-2041.

Gómez-García, E., Crecente-Campo, F., Barrio-Anta, M., and Diéguez-Aranda, U. (2015). A disaggregated dynamic model for predicting volume, biomass and carbon stocks in evenaged pedunculate oak stands in Galicia (NW Spain). Eur. J. For. Res. 134(3), 569-583.

Han, H.-S. and Kellogg, L. D. (2000). Damage characteristics in young Douglas-Fir stands from commercial thinning with four timber harvesting systems. West. J. Appl. For. 15(1), 27-33.

Hooke, R. and Jeeves, T. A. (1961). "Direct Search" solution of numerical and statistical problems. J. Assoc. Comput. Mach. 8, 212-229.

Kerr, G. and Haufe, J. (2011). Thinning Practice: A Silvicultural Guide. Ed. by Forestry Commision, 54 pages.

MAGRAMA (2012). Cuarto Inventario Forestal Nacional. Principado de Asturias. Ministerio de Agricultura, Alimentación y Medio Ambiente, 59 pages.

Miina, J. (1996). Optimizing thinning and rotation in a stand of Pinus sylvestris on a drained peatland site. Scand. J. For. Res. 11(1-4), 182-192.

Nocedal, J. and Wright, S. J. (2006). Numerical optimization. 2nd. Springer, xxii, 664 p. pages.

Pasalodos-Tato, M., Pukkala, T., Calama, R., Cañellas, I., and Sánchez-González, M. (2016). Optimal management of Pinus pinea stands when cone and timber production are considered. Eur. J. For. Res. 
Pukkala, T. and Kellomäki, S. (2012). Anticipatory vs adaptive optimization of stand management when tree growth and timber prices are stochastic. Forestry 85(4), 463-472.

Pukkala, T. (2009). Population-based methods in the optimization of stand management. Silva Fenn. 43(2), 261-274.

Pukkala, T., Lähde, E., and Laiho, O. (2014). Optimizing any-aged management of mixed boreal forest under residual basal area constraints. J. For. Res. 25(3), 627-636.

Rodríguez, R., Majada, J., Benito, J. L., and Braña, M. (2007). Manual básico de selvicultura del pino pinaster. Consejería de Medio Ambiente y Desarrollo Rural, Principado de Asturias, 87 pages.

Roise, J. P. (1986). A nonlinear programming approach to stand optimization. For. Sci. 32(3), $735-748$.

Russell, S. and Norvig, P. (2009). Artificial intelligence: a modern approach. Prentice-Hall, 1132 pages.

Storn, R. and Price, K. (1997). Differential evolution-a simple and efficient heuristic for global optimization over continuous spaces. J. Glob. Optim. 11(4), 341-359.

Tahvonen, O., Pihlainen, S., and Niinimäki, S. (2013). On the economics of optimal timber production in boreal Scots pine stands. Can. J. For. Res. 43(8), 719-730.

Talbi, E.-G. (2009). Metaheuristics: from design to implementation. Hoboken, New Jersey: John Wiley \& Sons, Inc., xxix +593 pages.

Valsta, L. (1993). Stand management optimization based on growth simulators. PhD thesis.

Weiskittel, A. R., Hann, D. W., Kershaw, J. A., and Vanclay, J. K. (2011). Forest growth and yield modeling. 1st. Chichester, UK: Wiley \& Sons, 415 pages.

Zadeh, L. and Polak, E. (1969). System theory. McGraw-Hill. 


\section{${ }_{533}$ Tables}

Table 1: Assortments, dimensions, and prices of Pinus pinaster Ait. in Asturias (simplification of Arias-Rodil et al., 2015b, without including log-length requirements)

\begin{tabular}{lll}
\hline Assortment & Top diameter limit $(d, \mathrm{~cm})$ & Price $\left(€ \mathrm{~m}^{-3}\right)$ \\
\hline Veneer and plywood & $d \geq 40$ & 60 \\
Sawlog & $15 \leq d<40$ & 40 \\
Pulpwood & $d<15$ & 25 \\
\hline
\end{tabular}


Table 2: Maximum value $\left(J_{\text {opt }}, € \mathrm{ha}^{-1}\right)$ of objective function (26) obtained with the three approaches (SQP, HJ, and DE -for the latter, the best result after 20 optimization runs is shown) for 16 example stands which differ in site index $(S)$ and number of stems per hectare at plantation $\left(N_{0}\right)$. For SQP and HJ, $n_{t}$ indicates the optimum number of thinnings. The number of function evaluations $\left(n_{\text {eval }}\right)$ used by each numerical method in every problem is also pointed out.

\begin{tabular}{|c|c|c|c|c|c|c|c|c|}
\hline \multirow[t]{2}{*}{$S$} & \multirow[t]{2}{*}{$N_{0}$} & \multirow[t]{2}{*}{$n_{t}$} & \multicolumn{2}{|c|}{ SQP } & \multicolumn{2}{|c|}{ HJ } & \multicolumn{2}{|c|}{$\mathrm{DE}$} \\
\hline & & & $J_{\text {opt }}$ & $n_{\text {eval }}$ & $J_{o p t}$ & $\overline{n_{\text {eval }}}$ & $J_{o p t}$ & $\overline{n_{\text {eval }}}$ \\
\hline \multirow{4}{*}{7} & 500 & 3 & -164.50 & 204 & -164.50 & 712 & -164.89 & 5915 \\
\hline & 900 & 3 & -1124.05 & 283 & -1124.05 & 763 & -1126.60 & 4305 \\
\hline & 1300 & 3 & -2049.88 & 297 & -2049.88 & 804 & -2056.97 & 3675 \\
\hline & 1700 & 3 & -2962.88 & 321 & -2962.88 & 746 & -2969.54 & 3990 \\
\hline \multirow{4}{*}{10} & 500 & 2 & 1986.08 & 185 & 1986.07 & 607 & 1982.99 & 4445 \\
\hline & 900 & 3 & 1003.96 & 214 & 1003.95 & 707 & 1001.16 & 4865 \\
\hline & 1300 & 3 & 41.48 & 225 & 41.47 & 636 & 41.36 & 6510 \\
\hline & 1700 & 3 & -923.35 & 277 & -923.35 & 756 & -925.11 & 4515 \\
\hline \multirow{4}{*}{13} & 500 & 1 & 4653.60 & 191 & 4653.60 & 611 & 4652.75 & 3640 \\
\hline & 900 & 2 & 3699.48 & 212 & 3699.48 & 605 & 3666.31 & 4165 \\
\hline & 1300 & 3 & 2659.33 & 212 & 2659.32 & 634 & 2651.23 & 4200 \\
\hline & 1700 & 3 & 1704.19 & 209 & 1704.19 & 709 & 1700.42 & 4690 \\
\hline \multirow{4}{*}{16} & 500 & 1 & 7800.39 & 180 & 7800.39 & 688 & 7798.66 & 3885 \\
\hline & 900 & 2 & 6842.63 & 179 & 6842.62 & 757 & 6836.32 & 3920 \\
\hline & 1300 & 2 & 5781.71 & 174 & 5781.71 & 555 & 5775.59 & 4025 \\
\hline & 1700 & 3 & 4798.14 & 197 & 4798.14 & 652 & 4784.64 & 3990 \\
\hline
\end{tabular}




\section{${ }_{534}$ List of Figures}

5351 Graph of function $J\left(t_{1}, I_{1}, t_{1}+5,0.45, t_{1}+10,0.45, t_{1}+15\right)$, the SEV when varying the timing $\left(t_{1}\right)$ and intensity $\left(I_{1}\right)$ of the first thinning (example stand of site index $S=13 \mathrm{~m}$ and number of trees per hectare at plantation $\left.N_{0}=1300\right)$. . . 


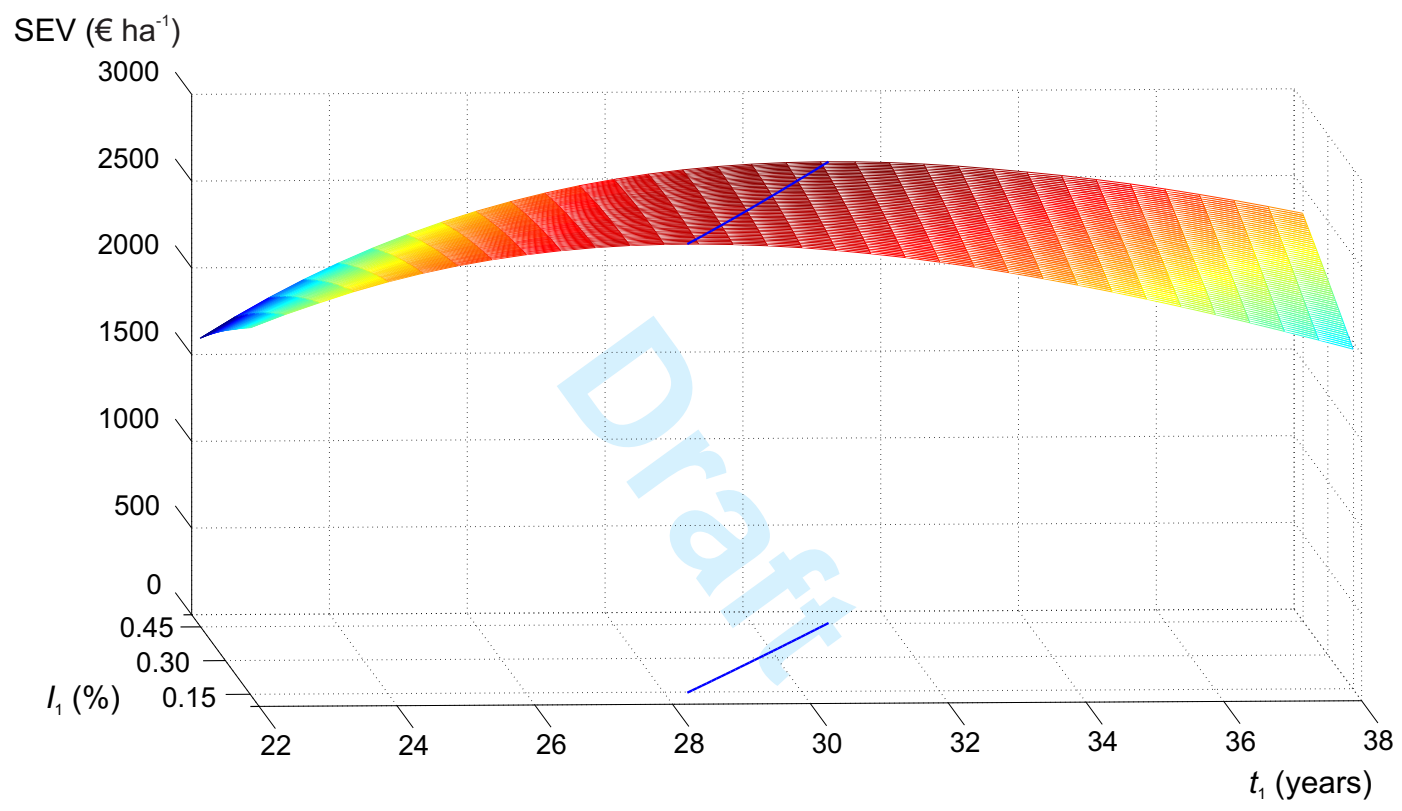

Figure 1: Graph of function $J\left(t_{1}, I_{1}, t_{1}+5,0.45, t_{1}+10,0.45, t_{1}+15\right)$, the SEV when varying the timing $\left(t_{1}\right)$ and intensity $\left(I_{1}\right)$ of the first thinning (example stand of site index $S=13 \mathrm{~m}$ and number of trees per hectare at plantation $\left.N_{0}=1300\right)$. 